\title{
Evaluation of Some Non Invasive Predictors for Presence of Esophageal Varices in Patients with Compensated HCV Positive Cirrhosis
}

\author{
Hoda AbdEl-Aziz Elhady, MD ${ }^{1}$, Ashraf A. Hammam, MD², Sahar A. Elnimr, MD ${ }^{3}$, Asmaa M. H. Osh, MD $^{4}$ \\ ${ }^{1,2}$ Internal Medicine Department, Faculty of Medicine, Zagazig University, Egypt \\ ${ }^{3}$ Tropical Medicine Department, Faculty of Medicine, Zagazig University, Egypt \\ ${ }^{4}$ Clinical Pathology Department, Faculty of Medicine, Zagazig University, Egypt
}

\begin{abstract}
Background: The current guidelines recommend the screening of all cirrhotic patients by endoscopy for esophageal varices (EV), but repeated endoscopic examinations are unpleasant for patients and have a high cost impact and burden on endoscopic units. Recognition of non-invasive predictors of $E V$ will allow upper gastrointestinal tract (GIT) endoscopy to be carried out only in a selected group of patients, thus avoid unnecessary intervention and at the same time not to miss patients at risk of bleeding. Aim: the aim of this study was to evaluate the validity of three non- invasive parameters in the prediction of esophageal varices in patients with compensated hepatitis $C$ virus $(\mathrm{HCV})+v e$ liver cirrhosis namely insulin resistance, platelet count/spleen diameter ratio and right liver lobe diameter/albumin ratio. Patients and Methods: This prospective study included one hundred non-diabetic, non-obese patients with Child A HCV induced cirrhosis. All studied patients underwent a detailed history, thorough physical examination, biochemical workup, upper gastrointestinal endoscopy and abdominal ultrasound. Insulin resistance (IR) by the homeostasis model assessment (HOMA), the platelet count/spleen diameter ratio and the right liver lobe diameter/albumin ratio for all patients were calculated. Results: The prevalence of esophageal varices in Child $\mathrm{A} H \mathrm{HCV}+v e$ cirrhosis were high. The three predictors demonstrated a high statistically significant correlation with the presence and grade of esophageal varices ( $P$ values $<0.001)$. Among the three non-invasive predictors, the HOMA-IR score gave the highest accuracy at a cut-off value of 3. The next highest accuracy was associated with the platelet count/spleen diameter ratio at a cut-off value of 750. The least accurate of the three non-invasive predictors was right liver lobe diameter /albumin ratio at a cut-off value of 3.5. Conclusion: Insulin resistance measured by HOMA-IR, Platelet count/Spleen diameter ratio, as well as the right liver lobe diameter/Albumin ratio are non-invasive parameters that can predict the presence and the grade of esophageal varices in patients with Child $\mathrm{A} H C V+v e$ cirrhosis and can help physicians to restrict the use of endoscopic screening only to patients presenting a high probability of esophageal varices. This is especially useful in clinical settings where resources are limited and endoscopic facilities are not present in all areas. Such the case in Egypt, where there is a large number of patients who require screening for esophageal varices.
\end{abstract}

Keywords: Esophageal varices, HCV +ve liver cirrhosis, Non invasive predictors.

\section{Introduction}

Approximately 170 million people worldwide are chronically infected by $\mathrm{HCV}$, which can result in progressive hepatic injury and fibrosis, resulting in cirrhosis and end-stage liver diseases [1]. Egypt receives the highest prevalence of HCV worldwide (15\%) [2]. In 2011 WHO, stat that Egypt has the highest prevalence in the world, which is $22 \%$ [3].

Portal hypertension $(\mathrm{PH})$, defined by a hepatic venous pressure gradient (HVPG) greater than $6 \mathrm{mmHg}$ is a common complication of cirrhosis. The development of EV is a clinical manifestation of $\mathrm{PH}$ with a prevalence that can range from $40 \%$ to $80 \%$ in patients with cirrhosis. This prevalence increases progressively in relation to the severity of liver damage [4].The clinical course of compensating cirrhosis classified according to presence of esophageal varices into compensating cirrhosis with absence (stage 1) or the presence of varices (stage 2) with significant morbidity and mortality rates in compensated cirrhotic patients with varices (stage 2) [5].

Upper gastrointestinal bleeding (UGB) caused by rupture of gastric and mainly EV are the most dramatic complication of cirrhosis with a mortality rate of $17 \%$ to $57 \%$ to this kind of patients [6]. HVPG and endoscopy are current gold-standard techniques to assess portal hypertension and EV. However, its use is limited by their invasiveness and screening all patients with endoscopy to guide therapy may significantly increase the cost [7].

Endoscopic screening of all patients with liver cirrhosis would result in a large number of unnecessary endoscopies and additional burden to endoscopy units [8].

In Egypt, the management of patients with liver cirrhosis complicated by the interplay between clinical, economic, social, and cultural factors and the generally poor compliance to both follow-up and treatment strategies [9].

Ideally, a method for identifying patients with EV should be simple, noninvasive, inexpensive, reproducible, accurate, and readily available; have high sensitivity and specificity; follow the natural history; reflect the effect of the treatment accurately; and indicate the prognosis and possibility of success of a treatment [7].

The aim of this study was to evaluate the validity of three non- invasive parameters in the prediction of esophageal 


\section{International Journal of Science and Research (IJSR)}

ISSN (Online): 2319-7064

Index Copernicus Value (2013): 6.14 | Impact Factor (2014): 5.611

varices in patients with compensated hepatitis $\mathrm{C}$ virus induced cirrhosis namely insulin resistance, platelet count/spleen diameter ratio and right liver lobe diameter/albumin ratio.

\section{Patients and Methods}

This is an observational, descriptive, analytical study carried out in the Gastroenterology and Hepatology unit, Internal Medicine Department in collaboration with Tropical Medicine and Clinical Pathology Departments, Faculty of Medicine, Zagazig University during the period from January 2012 to January 2015.

\section{Patients}

This study included 100 non-diabetic, non-obese patients with Child A HCV +ve cirrhosis who were under investigation and/or treatment in outpatient clinics, or patients referred to the hospital endoscopy unit for endoscopic screening for the presence of oesophageal varices. All patients signed informed consent before participating in this study.

\section{Inclusion Criteria}

Patients were included after they had a diagnosis of HCV $+v e$ cirrhosis based on histopathological examination of liver biopsy whenever available or clinical criteria based on (history, physical examination, laboratory parameters and imaging findings) [5].

\section{Exclusion Criteria}

Patients excluded if they had:

- Advanced cirrhosis (Child-Pugh classes B and C).

- Other causes of liver disease or mixed causes (alcohol abuse, hepatitis B, autoimmune liver disease, Wilson's disease, hemochromatosis, $\alpha-1$ antitrypsin deficiency).

- Current or previous history of ascites or hepatic encephalopathy.

- Portal hypertensive bleeding.

- Hepatocellular carcinoma.

- Portal vein thrombosis.

- Body mass index $\geq 30 \mathrm{~kg} / \mathrm{m}^{2}$

- Present history of diabetes or current treatment with any dosage of insulin or anti diabetic drugs.

- Previous or current treatment with beta-blockers, diuretics, or other vasoactive drugs.

\section{Methods}

All patients of the study subjected to the following:-

1) Full history and thorough physical examination.

2) Body mass index (BMI): calculated as weight in kilograms/ square of body height in meters.

3) Routine investigations: They have done according to the methods applied in the laboratories of Clinical Pathology Department, Faculty of Medicine, Zagazig University and included:

- Complete blood picture by automated blood counter (Sysmex KX-21).

- Liver function tests: by kinetic method by (Cobas ${ }^{\circledR}$ Integra 400 Plus).

- Renal function tests: by (Cobas ${ }^{\circledR}$ Integra 400 Plus).
- Coagulation profile: by (Sysmex® CA-1500)

4) Calculation of Child-Pugh Score [10].

5) Serum sample for:

- Viral markers for HCV and HBV by ELISA by (STATFAX 3000, USA).

- HCV RNA by Polymerase Chain Reaction (TAQMAN RT PCR).

- Fasting plasma glucose concentration (Cobas ${ }^{\circledR}$ Integra 400 Plus).

6) Pelvi-abdominal ultrasonography examination to:

- Evaluate finding that suggest cirrhosis.

- Measure the portal vein diameter.

- Measure longitudinal (bipolar) diameter of the spleen.

- Measure splenic vein diameter.

- Measure right liver lobe diameter in mid-clavicular line.

Abdominal and pelvic ultrasonography done using (Philips HDI 5000®)

7) Fibroscan: in patients without already done liver biopsy. It is a non- invasive, rapid and painless method allowing evaluation of liver fibrosis by measurement of liver stiffness. In cirrhotic patients (F3 \& F4) liver stiffness measurement ranges from 12.5 to $75 \mathrm{KPa}$.

8) Special Investigation: included

- Fasting insulin ( $\mu U / m l)$ immunoenzymetric assay: Kits manufactured by Monobind USA (AccuBind ELISA Microwells)

- Upper gastrointestinal endoscopy:

All patients received an upper gastrointestinal endoscopy: all endoscopies were performed in a single endoscopy unit by an experienced endoscopist using a flexible video gastroscope (Olympus Medical Systems, Japan) and (Pentax Medical Systems, Japan).

Esophageal varices were graded according to their size; a grading classification of I-IV was used [11].

Grade I: was used for varices in the level of mucosa.

Grade II: for varices smaller than $5 \mathrm{~mm}$ filling less than $1 / 3$ of the oesophageal lumen.

Grade III: for varices larger than $5 \mathrm{~mm}$ filling more than 1/3 of the esophageal lumen

Grade IV: for varices occupied more than $2 / 3$ of esophageal lumen.

- Liver biopsy.

Done guided by ultrasonography by core biopsy needle in a single radiology unit by an experienced radiologist.

- Insulin resistance (IR)

IR was determined by the homeostasis model assessment (HOMA) method by using the following equation: Insulin resistance $($ HOMA-IR $)=$ fasting insulin $\mu \mathrm{U} / \mathrm{ml}) \times$ fasting glucose $(\mathrm{mmol} / \mathrm{L})$ /22.5. Alternatively, fasting insulin $\mu \mathrm{U} / \mathrm{ml}) \times$ fasting glucose $(\mathrm{mg} / \mathrm{dl}) / 405$ [12].

- Calculation of the right liver lobe diameter (cm) / serum albumin concentration (gm/dl).

- Calculation of platelet count $\left(\mathrm{mm}^{3)} /\right.$ spleen bipolar diameter ( $\mathrm{mm})$.

\section{Statistical Analysis}

All statistical calculations were performed using computer programs Microsoft Excel 2007 (Microsoft Corporation, 


\section{International Journal of Science and Research (IJSR) \\ ISSN (Online): 2319-7064}

Index Copernicus Value (2013): 6.14 | Impact Factor (2014): 5.611

WA, USA) and SPSS (Statistical Package for the Social Science; SPSS Inc., Chicago, IL, USA) version 20 for Microsoft Windows.

\section{Results}

This study comprised 100 patients with Child A HCV +ve cirrhosis, 40 patients were included after they had been diagnosed as cirrhosis based on histopathological examination of liver biopsy, 60 patients were included after they had been diagnosed as cirrhosis based on history, physical examination, biochemical parameters, ultrasonographic finding and Fibroscan.

Table 1

\begin{tabular}{|c|c|}
\hline Variable & Number of Patients \% \\
\hline Age, years & $48.0 \pm 6.5$ \\
Mean \pm SD & $(23-57)$ \\
range & \\
Sex & $63(63 \%)$ \\
Male & $37(37 \%)$ \\
Female & \\
Body Mass Index kg/m ${ }^{2}$ & $27.1 \pm 1.7$ \\
Mean \pm SD & $(20-29.8)$ \\
range & \\
Body Mass Index kg/m $\mathbf{m}^{2}$ & $9(9 \%)$ \\
$<25$ & $91(91 \%)$ \\
$25-29.9$ & $13(13 \%)$ \\
Smoking &
\end{tabular}

Table 2

\begin{tabular}{|l|c|}
\hline \multicolumn{1}{|c|}{ Varices } & Number of Patients \% \\
\hline Oesophageal Varices (OV) present & \\
Yes & $79(79 \%)$ \\
No & $21(21 \%)$ \\
Grade of varices in 79 patients & \\
OV Grade I & $19(24 \%)$ \\
OV Grade II & $47(59.5 \%)$ \\
OV Grade III & $13(16.5 \%)$ \\
Gastric varices & $9(11.3 \%)$ \\
With OV Grade I & $5(6.3 \%)$ \\
With OV Grade II & $4(5 \%)$ \\
\hline
\end{tabular}

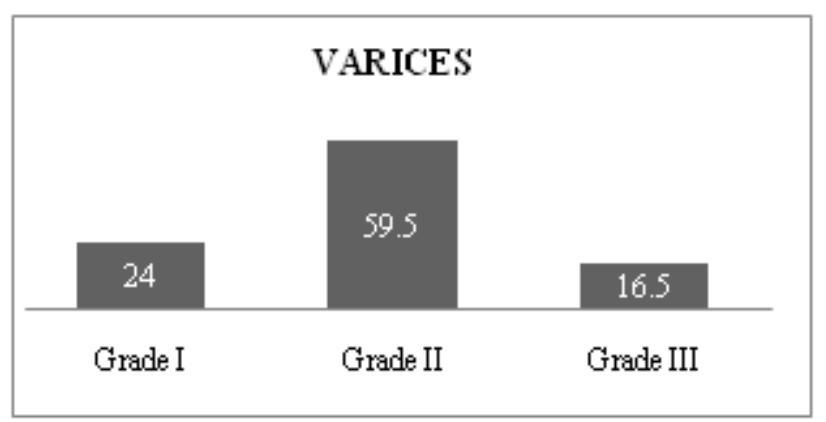

Figure 1
Table 1 shows the demographic parameters of all patients while Table (2) and Figure (1) shows The pattern of varices in all patients.

Table 3

\begin{tabular}{|c|c|}
\hline Variables & Mean \pm SD + Range \\
\hline WBCs $\times 10^{3} / \mathrm{ul}$ & $5.6 \pm 1.6(3.5-10)$ \\
$\mathrm{Hb}$ gm $/ \mathrm{dl}$ & $12.7 \pm 1.4(10.5-16)$ \\
$\mathrm{PLT}$ count $\times 10^{3} / \mathrm{ul}$ & $96.7 \pm 20.5(60-145)$ \\
$\mathrm{INR}$ & $1.16 \pm 0.1(1-1.3)$ \\
Albumin gm/dl & $3.87 \pm 0.4(3.4-4.6)$ \\
Bilirubin $\mathrm{mg} / \mathrm{dl}$ & $0.95 \pm 0.26(0.38-1.5)$ \\
Creatinine $\mathrm{mg} / \mathrm{dl}$ & $0.74 \pm 0.15(0.4-1.2)$ \\
Fasting plasma glucose mg/dl & $94.4 \pm 18.3(70-125)$ \\
Fasting Insulin $\mu \mathrm{U} / \mathrm{ml}$ & $18.98 \pm 11.9(6.2-70.6)$ \\
\hline
\end{tabular}

Hb: Hemoglobin, PLT: Platelet, INR: International Normalized Ratio

Table 4

\begin{tabular}{|l|c|}
\hline \multicolumn{1}{|c|}{ Variables } & Mean \pm SD + Range \\
\hline Portal vein diameter, mm & $12.5 \pm 1.6(10-17)$ \\
Spleen bipolar diameter, & $149.1 \pm 20.2(105-$ \\
mm & $220)$ \\
Right liver lobe diameter, & $149 \pm 21.1(130-230)$ \\
mm & \\
\hline
\end{tabular}

Table 5

\begin{tabular}{|c|c|}
\hline Variables & Mean \pm SD + Range \\
\hline HOMA-IR score & $4.36 \pm 2.6(1.22-15.6)$ \\
PLT count, $(\mathrm{n} / \mathrm{ul})$ / spleen diameter $(\mathrm{mm})$ & $657.2 \pm 191.6(352-1047)$ \\
ratio & \\
Right liver lobe, $\mathrm{cm} /$ albumin ratio $(\mathrm{gm} / \mathrm{dl})$ & $3.86 \pm 0.55(3.02-6.17)$ \\
\hline
\end{tabular}

HOMA-IR: Homeostasis Model Assessment Of Insulin

Resistance, PLT: Platelet, n: number

Table 3, Table 4 and Table 5 Shows Mean values \pm Standard Deviation (SD) of laboratory parameters, of Ultrasound Measurement and of the three non-invasive parameters of all patients respectivly. 
International Journal of Science and Research (IJSR)

ISSN (Online): 2319-7064

Index Copernicus Value (2013): 6.14 | Impact Factor (2014): 5.611

\begin{tabular}{|c|c|c|c|}
\hline Variable & $\begin{array}{c}\text { Patients Without } \\
\text { Esophageal Varices } \mathrm{N}=21 \\
(\text { Mean } \pm \mathrm{SD})\end{array}$ & $\begin{array}{c}\text { Patients with } \\
\text { Esophageal Varices } \mathrm{N}=79 \\
(\text { Mean } \pm \text { SD) }\end{array}$ & $\begin{array}{l}\text { Analysis of data } \\
t \text { test P -Value }\end{array}$ \\
\hline Age, years & $44.5 \pm 6.2$ & $48.9 \pm 6.3$ & 2.90 .004 \\
\hline Sex Male & $9(14.3)$ & $54(85.7)$ & $\mathrm{X}^{2}$ \\
\hline Female & $12(32.4)$ & $25(67.6)$ & 4.630 .03 \\
\hline Smoking No & $21(21.0)$ & $66(75.9)$ & \\
\hline Yes & $0(0.0)$ & $13(100.0)$ & 2.650 .1 \\
\hline Body Mass Index & $26.8 \pm 1.1$ & $27.3 \pm 1.8$ & 1.10 .26 \\
\hline WBCs $\times 10^{3} / \mathrm{ul}$ & $6.4 \pm 2.01$ & $5.4 \pm 1.5$ & 2.40 .017 \\
\hline $\mathrm{Hb} \mathrm{gm} / \mathrm{dl}$ & $13.3 \pm 1.1$ & $12.5 \pm 1.5$ & 2.240 .02 \\
\hline PLT count $\times 10^{3} / \mathrm{ul}$ & $118.2 \pm 19$ & $91 \pm 16.8$ & $6.39<0.001$ \\
\hline INR & $1.09 \pm 0.06$ & $1.2 \pm 0.07$ & $5.02<0.001$ \\
\hline Bilirubin mg/dl & $0.74 \pm 0.18$ & $1.0 \pm 0.25$ & $4.19<0.001$ \\
\hline Albumin gm/dl & $4.3 \pm 0.2$ & $3.76 \pm 0.3$ & $7.52<0.001$ \\
\hline Creatinine $\mathrm{mg} / \mathrm{dl}$ & $0.74 \pm 0.08$ & $0.74 \pm 0.16$ & 0.040 .96 \\
\hline Fasting Blood glucose $\mathrm{mg} / \mathrm{dl}$ & $87.4 \pm 13.5$ & $96.2 \pm 19$ & 1.990 .04 \\
\hline Fasting Insulin $\mu \mathrm{U} / \mathrm{ml}$ & $11.3 \pm 3.1$ & $21 \pm 12.5$ & $3.5<0.001$ \\
\hline Portal vein diameter, $\mathrm{mm}$ & $10.7 \pm 0.8$ & $13 \pm 1.4$ & $7.02<0.001$ \\
\hline Spleen bipolar diameter, $\mathrm{mm}$ & $133.5 \pm 14.1$ & $153.3 \pm 19.6$ & $4.3<0.001$ \\
\hline Right liver lobe diameter, $\mathrm{mm}$ & $151.2 \pm 19.2$ & $149 \pm 21.7$ & 0.520 .6 \\
\hline
\end{tabular}

WBCs: White Blood Cells, Hb: Hemoglobin, PLT: Platelet, INR: International Normalized Ratio

Table 6 Shows Univariate Analysis of Factors Associated with Presence of Varices.

Table 7:

\begin{tabular}{|c|c|c|c|}
\hline Variable & $\begin{array}{c}\text { Patients Without } \\
\text { Esophageal Varices N =21 } \\
(\text { Mean } \pm \text { SD) }\end{array}$ & $\begin{array}{c}\text { Patients with Esophageal } \\
\text { Varices N=79 } \\
(\text { Mean } \pm \text { SD) }\end{array}$ & $\begin{array}{c}\text { Analysis of data } \\
\mathrm{t} \text { test P Value }\end{array}$ \\
\hline HOMA-IR score & $2.2 \pm 0.6$ & $4.9 \pm 2.6$ & $4.6<0.001$ \\
PLT count, $\mathrm{n}$ / ul/spleen ratio, mm & $849.1 \pm 226$ & $606.1 \pm 144.6$ & $6.01<0.001$ \\
Right liver lobe, cm /albumin, gm/dl. ratio & $3.48 \pm 0.4$ & $3.96 \pm 0.5$ & $3.75<0.001$ \\
\hline
\end{tabular}

Table 8

\begin{tabular}{|l|c|c|}
\hline \multicolumn{1}{|c|}{ Variable } & Analysis of data & P - Value \\
& B Coefficient \pm Standard Error (SE) & \\
\hline Portal vein diameter & $0.13 \pm 0.07$ & 0.01 \\
HOMA-IR score & $0.008 \pm 0.005$ & 0.04 \\
PLT count, $\mathrm{n} / \mathrm{ul} /$ spleen ratio, $\mathrm{mm}$ & $0.02 \pm 0.014$ & 0.03 \\
Right liver lobe, $\mathrm{cm} /$ albumin $\mathrm{gm} / \mathrm{dl}$ ratio & $0.14 \pm 0.003$ & 0.001 \\
\hline
\end{tabular}

HOMA- IR: Homeostasis Model Assessment of Insulin Resistance, PLT: Platelet, n: Number

Table 7 Shows Univariate Analysis of the tested three noninvasive parameters and their association with Presence of Varices, while Table (8) Shows Multivariate Logistic
Regression Analysis of Factors Associated with Presence of Varices.

Table 9: Comparison of the (Mean \pm SD) of the Three Parameters and Pattern of Varices

\begin{tabular}{|c|c|c|c|}
\hline Pattern of Varices & $\begin{array}{c}\text { HOMA-IR } \\
(\text { Mean } \pm \text { SD) }\end{array}$ & $\begin{array}{c}\text { Platelet count /spleen ratio } \\
(\text { Mean } \pm \text { SD) }\end{array}$ & $\begin{array}{c}\text { Right liver lobe /albumin ratio } \\
\text { (Mean } \pm \text { SD) }\end{array}$ \\
\hline Patient with no varices & $2.2 \pm 0.6$ & $849.1 \pm 226.9$ & $3.48 \pm 0.4$ \\
Grade I & $4.86 \pm 2.9$ & $631.2 \pm 179.2$ & $3.9 \pm 0.35$ \\
Grade II & $4.9 \pm 2.7$ & $636.4 \pm 111.8$ & $3.95 \pm 0.55$ \\
Grade III & $5.05 \pm 1.9$ & $587.6 \pm 136.9$ & $4 \pm 0.65$ \\
Gastric varices & $5.75 \pm 1.8$ & $511.9 \pm 75.2$ & $4.1 \pm 0.7$ \\
\hline F & 7.72 & 17.5 & 5.09 \\
P- value & $<0.001$ & $<0.001$ & 0.003 \\
\hline
\end{tabular}

Table (9) shows that, when we compared the mean values of HOMA-IR score, platelet count/spleen diameter ratio between pateints with no varices and pateints with different grades of varices highly significance were noted with $(\mathrm{P}<$ $0.001)$, and when we compared the mean values of right liver lobe diameter /albumin ratio between pateints with no varices and pateints with different grades of varices also, significance were noted with $(\mathrm{P}=0.003)$.
Table 10: Least Significant Difference of the Three Parameters and Pattern of Varices

\begin{tabular}{|c|c|c|c|}
\hline & Patient with no varices & Grade I & Grade II \\
\hline Grade III & $\mathrm{P}<0.001$ & $\mathrm{P}<0.05$ & NS \\
\hline Grade II & $\mathrm{P}<0.001$ & NS & \\
\hline Grade I & $\mathrm{P}<0.001$ & & \\
\hline
\end{tabular}

NS: not significant 


\section{International Journal of Science and Research (IJSR) \\ ISSN (Online): 2319-7064}

Index Copernicus Value (2013): 6.14 | Impact Factor (2014): 5.611

Table (10) shows the least significant difference (LSD) of the means of the three parameters, there were significant difference between pateints with no varices and pateints with different grades of varices. Also, between the pateints with grade I varices and pateints with grade III varices. But, there were no significant difference between pateints with grade I varices and pateints with grade II of varices as well as between pateints with grade II varices and pateints with grade III of varices

Table 11: Correlations between the Three Parameters and

\begin{tabular}{|c|c|c|} 
Grades of Varices \\
\hline & $\begin{array}{c}\text { Correlation } \\
\text { Coefficient }(r)\end{array}$ & $\begin{array}{c}P- \\
\text { Value }\end{array}$ \\
\hline HOMA-IR score & +0.4 & $<0.001$ \\
\hline PLT count, $\mathrm{n} / \mathrm{ul} /$ spleen ratio, mm & -0.39 & $<0.01$ \\
\hline Right liver lobe,cm/albumin gm/dl ratio & +0.35 & $<0.05$ \\
\hline
\end{tabular}

Table (11) shows the correlations between the three parameters and grades of varices, there are positive correlation between HOMA-IR score and grades of varices (Correlation Coefficient $(\mathrm{r})=+0.4$; P- Value $<0.001)$ as well as a positive correlation between right liver lobe diameter /albumin ratio and grades of varices $(\mathrm{r}=+0.35 ; \mathrm{P}$ $<0.05)$, there are negative correlation between platelet count/spleen bipolar diameter ratio and grades of varices $(r=$ $-0.39 ; \mathrm{P}<0.01)$.

HOMA- IR: Homeostasis Model Assessment of Insulin

Resistance, PLT: Platelet, n: number

Table 12: The Accuracy of the three parameters in Predicting the Presence of Oesophageal and Gastric Varices.

\begin{tabular}{|c|c|c|c|c|c|c|}
\hline $\begin{array}{c}\text { Platelet } \\
\text { count/spleen ratio }\end{array}$ & Cut off point & Sensitivity (\%) & Specificity (\%) & $\begin{array}{c}(+) \text { ve predictive } \\
\text { value (\%) }\end{array}$ & $\begin{array}{c}(-) \text { ve predictive } \\
\text { value (\%) }\end{array}$ & Accuracy (\%) \\
\hline & 750 & 81 & 81 & 94.1 & 53.1 & 81 \\
\hline $\begin{array}{c}\text { right liver lobe / } \\
\text { albumin ratio }\end{array}$ & 3.5 & 78.5 & 57.1 & 87.3 & 41.4 & 74 \\
\hline HOMA-IR score & 3 & 88.6 & 95.2 & 98.6 & 69 & 90 \\
\hline
\end{tabular}

Table (12) shows that, as regard analysis of a platelet count/spleen ratio. The value greater than 750 [ sensitivity, $81 \%$; specificity, $81 \%$; positive predictive value $94.1 \%$; negative predictive value $53.1 \%$ and accuracy $81 \%$ ] is the best cut off for predicting the presence of $\mathrm{EV}$, for a right liver lobe / albumin ratio. the value greater than 3.5 [ sensitivity, $78.5 \%$; specificity, $57.1 \%$; positive predictive value $87.3 \%$; negative predictive value $41.4 \%$ and accuracy $74 \%$ ] is the best cutoff for predicting the presence of EV. About HOMA-IR score, The value greater than 3 [ sensitivity, $88.6 \%$; specificity, $95.2 \%$; positive predictive value $98.6 \%$; negative predictive value $69 \%$ and accuracy $90 \%$ ] is the best cutoff for predicting the presence of EV. 
International Journal of Science and Research (IJSR)

ISSN (Online): 2319-7064

Index Copernicus Value (2013): 6.14 | Impact Factor (2014): 5.611

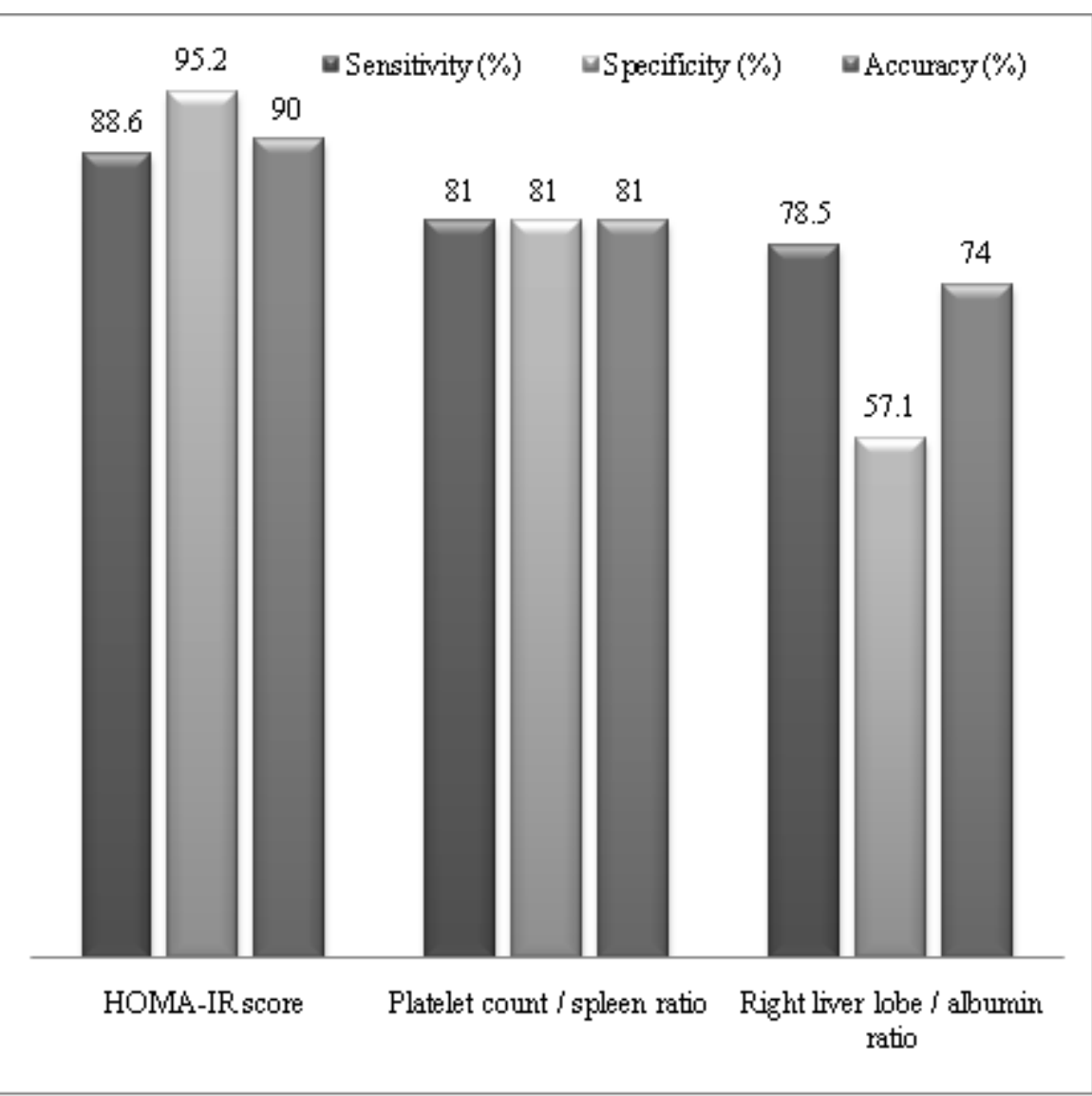

Figure 5: Comparisons among the Sensitivity, Specificity, and Accuracy of the Three Parameters in Predicting the Presence of Varices.

HOMA-IR: Homeostasis Model Assessment of Insulin Resistance

(Figure 5) shows that, among the 3 non-invasive predictors, the HOMA-IR score gave the highest accuracy at a cut-off value of 3. The next highest accuracy was the platelet count/spleen diameter ratio at a cut-off value of 750 . The least accurate of the 3 non-invasive predictors was right liver lobe diameter /albumin ratio at a cut-off value of 3.5 .

\section{Discussion}

Because of the impact of UGB caused by rupture of EV in the prognosis of cirrhotic patients, the Baveno IV 2005 Consensus Workshop [13] and the American Association for the Study of Liver Diseases (AASLD) have determined that every patient diagnosed with cirrhosis should be investigated for EV, regardless of Child class and cause. In patients who have compensated cirrhosis and no varices on the initial EGD, it should be repeated in 3 years. If there is evidence of hepatic decompensation, EGD should be done at that time and repeated annually [14].

Several non-invasive methods have emerged in recent years, assessing the potential of various laboratory, clinical, and ultrasonographic parameters, linked directly or indirectly to portal hypertension including:Thrombocytopenia, splenomegaly [15]. AST/ALT ratio [16], AST to platelets ratio index (APRI) [17], platelets count to spleen diameter ratio [18], The right liver lobe diameter/albumin index [11],
Transient elastography [19], Forns Index [20], Lok score [21] and Insulin resistance [22].

This study was conducted on 100 non-diabetic, non-obese patients with Child A HCV induced cirrhosis with forty patient had a diagnosis of HCV induced cirrhosis based on histopathological examination of liver biopsy and sixty patient had a diagnosis of cirrhosis based on physical findings, laboratory investigations, and ultrasonographic findings because of absence of liver biopsy.

In this study, the prevalence of EV in Child A HCV +ve cirrhosis were high, as 79 patients had esophageal varices (79\%), 9 of them had also gastric varices.

Garcia-Tsao et al., (2007) stated that, gastroesophageal varices are present in approximately $50 \%$ of patients with cirrhosis. Their presence correlates with the severity of liver disease with $40 \%$ of Child A patients have varices.

The prevalence of oesophageal varices in cirrhotic patients may reach up to $80 \%$ in some studies [8]. Camma et al., $^{2}$ (2009) studied 104 newly diagnosed patients with Child A HCV cirrhosis, identified that $60 \%$ of patients $(63 / 104)$ had EV.

In a multi-centered study conducted In 3 centers ( 2 in Spain and 1 in Egypt) on 2 sets of newly diagnosed cirrhotic patients (total $n=357$ ) EV was recorded in $75 \%$ of patients of first set and in $76 \%$ in second set [23]. 


\section{International Journal of Science and Research (IJSR) \\ ISSN (Online): 2319-7064}

Index Copernicus Value (2013): 6.14 | Impact Factor (2014): 5.611

Another studies done on Egyptian patients stated that the prevalence of esophageal varices in cirrhosis was $83 \%$ and $82 \%$. [24, 25].

Univariate analysis of factors associated with presence of varices showed that, patients who got EV were characterized by being, older, males more than females, more smoker, with higher body mass index, lower Platelet counts, higher fasting insulin level, higher fasting blood glucose, higher spleen diameter, higher portal vein diameter.

Several studies have shown that high portal vein diameter [26], splenomegaly [27] and low platelet count [28] serve as predictors of EV presence.

In this study, as well, the tested three parameters with high HOMA-IR score, low platelet count/spleen diameter ratio and high right liver lobe diameter /albumin ratio were all also associated with the presence and grade of varices.

However, by multivariate logistic regression analysis of factors associated with presence of varices only 4 features were independently linked to the presence of varices: high Portal vein diameter [ P- Value $=0.01]$, high HOMA-IR [ $\mathrm{P}$ - Value $=0.04]$, low platelet count/spleen bipolar diameter ratio [ $\mathrm{P}$ - Value $=0.03$ ], and high Right liver lobe diameter /albumin ratio [P- Value $=0.001]$.

Giannini et al., (2003) introduced the use of the platelet count/spleen diameter ratio as a tool to predict oesophageal varices. This ratio links thrombocytopenia to splenomegaly to introduce a variable that takes into consideration that thrombocytopenia is mainly due to hypersplenism secondary to portal hypertension. In that study, when a cut-off value of 909 used, the sensitivity was $100 \%$, and the specificity was 93\% [29].

Giannini et al., (2006) reported the results of a multicentre study to validate the use of platelet count/spleen diameter ratio in the prediction of esophageal varices. At a cut-off value of 909 , the sensitivity was $92 \%$, and the specificity was $67 \%$ Patient having the ratio greater than cut-off value should not receive nonselective beta-blockers prophylactic therapy because they are less likely to develop esophageal varices. These patients should less frequently undergo endoscopy.

Several studies have been performed using different best cut-off values to investigate this parameter as a noninvasive predictor for esophageal varices.

Agha et al., (2009) studied 114 patients with compensated HCV related cirrhotics, 909 cut-off showed negative predictive value $100 \%$ and a positive predictive value of $93.8 \%$ for the diagnosis of $\mathrm{EV}$.

Camma et al., (2009) studied 104 newly diagnosed patients with Child A HCV +ve cirrhosis, identified a value of 792 as the best cutoff for the presence of esophageal varices and ratio greater than 792 Could be useful to identify patients at low risk of EV. and stated That different results are perhaps related to differences in etiology and class of disease between the two populations as regard Giannini et al study.
One study on Egyptian patients (Esmat et al., 2012) concluded that a cut-off value of 1326.58 for the platelet count/spleen diameter ratio was used with a resulting $96.34 \%$ sensitivity, $83.33 \%$ specificity and $94 \%$ accuracy.

In another study also done on Egyptian patients ( $\boldsymbol{A} \boldsymbol{b} \boldsymbol{u} \boldsymbol{E l}$ Makarem et al., 2011) concluded that a cut-off value of 939.7 for the platelet count/spleen diameter ratio was used with a resulting $100 \%$ sensitivity, $86.3 \%$ specificity and $96.5 \%$ accuracy.

In this study, the cut-off value of the platelet count/spleen diameter ratio (750) was the optimal value for accurate prediction of EV with a resulting $81 \%$ sensitivity, $81 \%$ specificity and $81 \%$ accuracy.

When we applied the same cut-off value of 909 Giannini used for the platelet count/spleen diameter ratio to the current study, the sensitivity and accuracy was significantly reduced to $65 \%$ and $73 \%$, respectively.

The differences between the best cut-off values, sensitivity, specificity, and accuracy in this study and other studies may be attributed to several factors influencing the platelet count including infection, bleeding, drugs, and lower thrombopoietin levels in patients with liver cirrhosis. In addition, the absence of interobserver agreement between the sonographers and endoscopists of the different studies which can affect the results.

Regarding the right liver lobe diameter /serum albumin ratio Alempijevic et al., (2007) had counted an original ratio. For the first time they reported the value of the right liver lobe diameter /serum albumin concentration in assessment of portal hypertension. They used serum albumin concentration as a parameter of liver function in combination with right liver lobe size and used this ratio as a non-invasive predictor of esophageal varices with at a cut-off value of 4.425 , the sensitivity was $83.1 \%$, and the specificity was $73.9 \%$.

In another study on Egyptian patients Esmat et al.,( 2012) concluded that a cut-off value of 4.422 for the right liver lobe diameter/albumin concentration ratio gave sensitivity $91.46 \%$, and the specificity $77.78 \%$.

In this study, the cut-off value for the right liver lobe diameter/albumin concentration ratio (3.5) was the optimal value for accurate prediction of EVs with a resulting 78.5\% sensitivity, $57.1 \%$ specificity, and $74 \%$ accuracy.

The results of this study are the same results of other study on Egyptian patients done by (Adel and George, 2011). They investigate the right liver lobe diameter/albumin concentration ratio as a non-invasive predictor of esophageal varices, with the best cut off value at 3.5 where sensitivity was $80 \%$ and specificity was $70 \%$.

When we applied the same cut of value of 4.425 roported by Alempijevic et al.,(2007) used for the right liver lobe diameter/albumin ratio to the current study, the sensitivity, and accuracy was significantly reduced to $12.7 \%$ and $31 \%$, respectively. 


\section{International Journal of Science and Research (IJSR) \\ ISSN (Online): 2319-7064}

Index Copernicus Value (2013): 6.14 | Impact Factor (2014): 5.611

The differences between the best cut-off values, sensitivity, specificity, and accuracy in this study and Alempijevic study may be attributed to the different group of patient as all patients in this study were child A with the mean albumin concentration $(3.87 \pm 0.4)$ but In the other study, the patients were child $\mathrm{A}, \mathrm{B}$ and $\mathrm{C}$ with the mean albumin concentration (3.08 \pm 0.8), also patients were have different ethnic background. In addition, the differences between the sonographers of different studies, which can affect the results. This suggests the need for further multicenter studies including a large number of patients with different ethnic background for determining the best cut-off, value for that ratio.

Lastly, Insulin resistance which was firstly introduced by (Camma`et al., 2009), they stated that Insulin resistance measured by HOMA-IR, regardless of the presence of diabetes, significantly predicts the presence of $\mathrm{EV}$.

Studies in chronic liver diseases have shown a strong and independent pathogenic link between Insulin resistance (IR) and $\mathrm{HCV}$ infection and between IR and the severity of hepatic fibrosis[33].

Retrospective analyses have estimated that approximately $21-24 \%$ of chronic hepatitis $\mathrm{C}$ (CHC) patients are diabetic, with as many as $54 \%$ demonstrating IR [34].

Camma et al., (2009) studied 104 patients of Child A HCV + ve cirrhosis concluded that HOMA-IR score of greater than 3.5 is the cut-off value with the best sensitivity $61 \%$ and specificity $76 \%$ for predicting EV presence and HOMA score less than 3.5 (if non-diabetic) could be useful to identify patients at low risk of EV.

This finding has been validated positively in another independent cohort of 340 patients with cirrhosis. Moreover, there was a positive correlation with the HOMA score and worsening of the hepatic function [35].

Eslam et al., (2013), also concluded that in patients with cirrhosis, the presence of esophageal varices was independently associated with lower platelet count and raised HOMA score with HOMA score correlates with HVPG and independently predict clinical outcomes in these patients .

In this study, the cut-off value for HOMA-IR score of greater than 3 was the optimal value for accurate prediction of EV with a resulting $88.6 \%$ sensitivity, $95.2 \%$ specificity, and $90 \%$ accuracy.

When we applied the same cut-off value of 3.5 that Camma' et al used for the HOMA-IR score to this study, the sensitivity and accuracy was reduced to $65 \%$ and $73 \%$ respectively.

The differences between the best cut-off values, sensitivity, specificity, and accuracy in this study and Camma' et al study may be attributed to the different ethnic group of the patients, all patients in this study were non-diabetic and nonobese. Where in Camma' et al study 27 patients were diabetic and 11 patients were obese, and may be due to different genotype of $\mathrm{HCV}$ in studied groups where genotype 1 predominate Camma 'et al study and genotype 4 mostly predominate our study.

The limitations of the present study includes: relatively small number of patients, liver biopsy was not done in all patient and the diagnosis of cirrhosis was based on clinical, laboratory results and imaging findings in sixty patients.

On conclusion, insulin resistance measured by HOMA-IR, Platelet count/Spleen diameter ratio, as well as the right liver lobe diameter/Albumin ratio are non-invasive parameters that can predict the presence and grade of esophageal varices in patients with Child A HCV + ve cirrhosis.

The HOMA-IR score gave the highest accuracy (90\%) at a cut-off value of 3 with (sensitivity $88.6 \%$ and specificity $95.2 \%)$. The next highest accuracy was the platelet count/spleen diameter ratio $(81 \%)$ at a cut-off value of 750 with (sensitivity $81 \%$ and specificity $81 \%$ ). The least accurate of the 3 non-invasive parameters was right liver lobe diameter /albumin ratio (74\%) at a cut-off value of 3.5 with (sensitivity $78.5 \%$ and specificity $57.1 \%$ ).

This is of a value to reserve endoscopy for only those patients who have a high probability of having varices, particularly in Egypt where the resources are limited and where endoscopy is not available in all areas.

\section{Recommendations}

Additional studies are required in a larger sample of Child A $\mathrm{HCV}$-related liver cirrhosis patients for validation of these parameters as noninvasive predictors of oesophageal varices. In addition, those studies are necessary to determine a universal best cut-off values that can be safely recommended for the non-invasive diagnosis of oesophageal varices in these patients.

\section{References}

[1] Thomas DL and Seeff LB: Natural history of hepatitis C. Clin Liver Dis; (2005) 9: 383-398.

[2] Egyptian Ministry of Health: Egyptian Ministry of Health Annual Report. Available at $<$ http://www.mohp.gov.eg/ Main.asp>.(2007)

[3] WHO: Factsheet No164, available at http://www.who.int/mediacentre/factsheets/fs164/en/ (2011)

[4] MerliM, Nicolini G, Angeloni S et al.: Incidence and natural history of small esophageal varices in cirrhotic patients. J Hepatol; (2003) 38:266

[5] Gomez EV, Rodriguez YS and Bertot LC.: Athe natural history of compensated HCV-related cirrhosis: A prospective long-term study. Journal of Hepatology; (2013) 58 (3) : 434-444.

[6] Giannini EG, Botta F, Borro P, et al.: Application of the platelet count/spleen diameter ratio to rule out the presence of oesophageal varices in patients with cirrhosis: a validation study based on follow-up. Dig Liver Dis; (2005) 37: 779-85.

[7] Berzigotti A, Seijo S, Reverter E, et al.: Assessing portal hypertension in liver diseases Expert Rev. Gastroenterol. Hepatol; (2013) 7(2):141-155.

\section{Volume 5 Issue 1, January 2016}




\section{International Journal of Science and Research (IJSR) \\ ISSN (Online): 2319-7064 \\ Index Copernicus Value (2013): 6.14 | Impact Factor (2014): 5.611}

[8] deFranchis R: Noninvasive diagnosis of esophageal varices: is it feasible? Am JGastroenterol; (2006) 101(11): 2520-2.

[9] Abu El Makarem MA, Shatat ME, Shaker Y, et al.: Platelet count/bipolar spleen diameter ratio for the prediction of esophageal varices: The special Egyptian situation Hepat Mon; (2011) 11(4): 278-284.

[10] Pugh RN, Murray-Lyon IM, Dawson JL et al.:Transection of the oesophagus for bleeding oesophageal varices. Br J Surg; (1973) 60:646-649.

[11] Alempijevic T, Bulat V, Djuranovic S, et al.: Right liver lobe/albumin ratio: Contribution to non-invasive assessment of portal hypertension. World J Gastroenterol; (2007) 13(40): 5331-5335.

[12] Matthews DR, Hosker JP, Rudenski AS et al.: Homeostasis model assessment: insulin resistance and beta cell function from fasting plasma glucose and insulin concentrations in man. Diabetologia ; (1985) 28:412-9.

[13] De Franchis R: Evolving consensus in portal hypertension report of the Baveno IV consensus workshop on methodology of diagnosis and therapy in portal hypertension. J Hepatol; (2005) 43:167-76.

[14] Garcia-Tsao G, Sanyal AJ, and Grace ND: The Pratice Guidelines Committee of the American Association for the Study of Liver Diseases, the Practice Parameters Committee of the American College of Gastroenterology Prevention and management of gastroesophageal varices and variceal hemorrhage in cirrhosis. Hepatology;(2007) 46:922-938.

[15] Thomopoulos K, Labropoulou K, Mimidis K, et al.: Non- Invasive predictors of the presence of large esophageal varices in patients with cirrhosis. Dig and Liver Dis; (2003) 35: 473-8.

[16] Giannini E, Risso D, Botta F, et al.: Validity and clinical utility of the aspartate aminotransferase-alanine aminotransferase ratio in assessing disease severity and prognosis in patients with hepatitis $\mathrm{C}$ virus-related chronic liver disease. Arch Intern Med; (2003)163: 218224.

[17] Wai CT, Greenson JK, Fontana RJ, et al.: A simple noninvasive index can predict both significant fibrosis and cirrhosis in patients with chronic hepatitis $\mathrm{C}$. Hepatology; (2003) 38:518-526.

[18] Giannini EG, Zaman A, Kreil A, et al.: Platelet count/spleen diameter ratio for the noninvasive diagnosis of esophageal varices: results of a multicenter, prospective, validation study. Am J Gastroenterol; (2006) 101: 2511-2519.

[19] Castera L, Pinzani M and Bosch J.: Non invasive evaluation of portal hypertension using transient sselastography Journal of Hepatology vol; (2012) $56 \mathrm{j}$ : 696-703

[20] Forns X, Ampurdanes S L, lovet JM, et al.: Identification of chronic hepatitis $\mathrm{C}$ patients without hepatic fibrosis by a simple predictive model. Hepatology; (2002) 36: 986-992.

[21] Lok AS, Ghany MG, Goodman ZD, et al.: Predicting cirrhosis in patients with hepatitis $\mathrm{C}$ based on standard laboratory tests: results of the HALT-C cohort. Hepatology; (2005) 42:282-292.

[22] Cammà C, Petta S, Di Marco V, et al.: Insulin resistance is a risk factor for esophageal varices in hepatitis C virus cirrhosis. Hepatology; (2009) 49: 195203.

[23] Eslam M , Ampuero J, Jover M, et al.: Predicting portal hypertension and variceal bleeding using noninvasive measurements of metabolic variables. Ann Hepatol; (2013) 12(4):588-98.

[24] Yosry A, Fouad R, Abdel Bary M et al.,: Non Invasive Prediction of Varices in Egyptian Cirrhotic Patients. Med. J. Cairo Univ., (2009) Vol. 77, No. 1, June: 343-349.

[25] Esmat S and Omran D: Study of Noninvasive Predictors of Portal Hypertension in Liver Cirrhotic Egyptian Patients. Journal of American Science; (2011) 7(1):962-968.

[26] Schepis F, Camma C, Niceforo D, et al.: Which patients with cirrhosis should undergo endoscopic screening for esophageal varices detection? Hepatology; ( 2001) 33:333-338.

[27] Sharma SK and Aggarwal R: Prediction of large esophageal varices in patients with cirrhosis of the liver using clinical, laboratory and imaging parameters. J Gastroenterol Hepatol; (2007) 22:1909-1915.

[28] Madhotra R, Mulcahy HE, Willner I, et al.: Prediction of esophageal varices in patients with cirrhosis. J Clin Gastroenterol; (2002) 34:81-5.

[29] Giannini E, Botta F, Borro $\mathbf{P}$ et al.: Platelet count/spleen diameter ratio: proposal and validation of a noninvasive parameter to predict the presence of oesophageal varices in patients with liver cirrhosis. Gut; (2003) 52(8): 1200-1205.

[30] Agha A, Anwar E, Bashir K,et al.: External validation of the platelet count/spleen diameter ratio for the diagnosis of esophageal varices in hepatitis $\mathrm{C}$ virusrelated cirrhosis. Dig Dis Sci; (2009) 54:654-60.

[31] Esmat s, Omarn D and Rashid L: Can we consider the right hepatic lobe size/albumin ratio a noninvasive predictor of oesophageal varices in hepatitis $\mathrm{C}$ virusrelated liver cirrhotic Egyptian patients? European Journal of Internal Medicine; (2012) 23: 267-272.

[32] Adel AM and George SR: A novel non-invasive Ratio for oesophageal varices prediction in $\mathrm{HCV}$ liver cirrhosis Egyptian patients. Journal of American Science; (2011) 7 (11):13-19. (ISSN: 1545-1003).

[33] Moucari R, Asselah T, Cazals-Hatem D, et al.: Insulin resistance in chronic hepatitis $\mathrm{C}$ : association with genotypes 1 and 4, serum HCV RNA level, and liver fibrosis. Gastroenterology; (2008) 134:416-423.

[34] Imazeki F, Yokosuka O, Fukai K, et al.: Prevalence of diabetes mellitus and insulin resistance in patients with chronic hepatitis $\mathrm{C}$ : comparison with hepatitis $\mathrm{B}$ virus-infected and hepatitis $\mathrm{C}$ virus-cleared patients. Liver Int; (2008) 28(3): 355-362.

[35] Li X, Wu K, and Fan D: Insulin resistan and platelet count/spleen diameter ratio: two simple, easy-to-get tests for predicting esophageal varices in cirrhosis. Hepatology (2009) 49: 1394-1395. 